\title{
Morbidity and health care utilisation among elderly people in Mmankgodi village, Botswana
}

\author{
Fredrik Clausen, Edwin Sandberg, Benedicte Ingstad, Per Hjortdahl
}

\begin{abstract}
Objective-To evaluate the health status among the elderly in a village in Botswana and their pattern of health care utilisation.
\end{abstract}

Design-A descriptive study where all persons 60 years and older were invited to participate, including a medical examination, laboratory testing and a questionnaire aiming at gathering sociodemographic data.

Setting-Mmankgodi village of Botswana. Subjects-419 persons were identified as elderly in the village, out of which 337 were included.

Main outcome measures-The general medical examination also included eye status, vision and hearing tests, nutritional status, blood pressure and registering of physical disabilities. Laboratory tests included haemoglobin, blood glucose, HIV antibodies and serum lipids. The questionnaire contained questions regarding family and civil status, self assessed general health, health problems experienced during the previous month, and health care utilisation. Questions also pertained to smoking, taking snuff, and alcohol consumption.

Results-A majority (75\%) of the elderly experienced good or only somewhat reduced health, while one quarter suffered more serious health problems. The most frequent health problems were related to the musculoskeletal system. Eye diseases, including cataract and blindness, were also common. The concentration of serum lipids is lower than the one found in the elderly population of Norway. Nutritional status indicated a relatively high prevalence $(7 \%)$ of malnutrition. The majority of men were still married $(87 \%)$, while most women were widowed $(71 \%)$. Women reported more health problems than men, and they also reported more worries regarding their own life situation. There is a tendency for the elderly to seek assistance from the established clinics and other health facilities for their health problems. Worries are either kept to themselves or advice is sought from relatives. Traditional healers were not often consulted for health problems or worries.

Conclusions-Major health problems were identified among the elderly in this geographical area of Botswana. There is presently no health programme in Botswana aimed at the elderly. Some of the diseases and conditions found in this study could easily be identified and treated in the present health system through a health care programme. (F Epidemiol Community Health 2000;54:58-63)

An increasingly aging population has recently become a focus in developing countries. ${ }^{1}$ An awareness of the effect on the population pyramid attributable to better health care and improved living conditions combined with a projected decrease in fertility, is by some seen as a problem that may appear in the near future. An increasing urbanisation and emphasis on the nuclear family and individualism, have made many people, and also some African governments, fear that the care taking family system may not be the support system one would like it to be.

In these perspectives it becomes important to know more about the situation of elderly people in developing countries. How do they live and who is supporting them? How is their health condition?

The project "Care for the elderly-Care by the elderly" was started as a part of a cooperation programme on health research between the University of Oslo, Norway and the University of Botswana in 1991. The topic of the study was indicated by the Ministry of Health. The study consists of three main components: a household study, a qualitative anthropological study and a medical study. Methods used were in depth interviews, focus group interviews and participatory observations over a 12 month period. The results from the non-medical part of the study have been published elsewhere, ${ }^{23}$ although they have been briefly summarised under Results. The aim of the medical part was to evaluate the health among the elderly in Botswana and their pattern of health care utilisation. The Government has indicated a need to gather baseline data of the elderly's health and living conditions, to be able to make plans for the elderly.

\section{Methods}

The village of Mmankgodi was chosen. It is close enough to the capital to be influenced by the ongoing modernisation process, yet far enough away $(60 \mathrm{~km})$ to be a rural village where traditions are important. Mmankgodi has one public clinic open seven days a week run by nurses, and visited by a general practitioner on a monthly basis. The limited size of Mmankgodi (4093 inhabitants, 1991 census) made it possible to aim at including all people aged 60 years or more, our definition of an "elderly". 
The medical study was divided into three main sections: (1) a general medical examination; (2) blood sampling for laboratory testing; (3) a questionnaire.

The three different ways of gathering data will add to each other and finally give a broad basis of knowledge of the elderly's health and living conditions.

The medical examination was carried out by three Norwegian doctors, but as many as $94 \%$ of the participants were seen by one doctor (Dr E Sandberg). Most of the examinations were carried out in the Mmankgodi clinic, only a few patients with severe disabilities were seen in their homes. An interpreter was used during the examinations.

The calculation of $95 \%$ confidence intervals (CI) has been done for the major findings.

MEDICAL EXAMINATION

All participants received a general physical examination that included an eye status with fundoscopy, tonometry for evaluating the eye pressure and a vision test by finger counting. Hearing was evaluated by whispering test. Hypertension was defined as blood pressure of $160 / 95 \mathrm{~mm} \mathrm{Hg}$ and above according to WHO standards for those 60 years of age or older. ${ }^{5}$ Blindness had a cut off point at finger counting less than one metre. Glaucoma was diagnosed when the eye pressure was $>25 \mathrm{~mm} \mathrm{Hg}$ on one or both eyes. Assessment of the nutritional status was done using the body mass index (BMI) as a reference. A BMI less than 16.0 represents severe chronic energy deficiency, and people with BMI more than 30 are considered as obese. $^{6}$

LABORATORY TESTING

The following blood tests were included: haemoglobin $(\mathrm{Hb})$; blood glucose, non-fasting; HIV antibody test; serum cholesterol and triglycerides: non-fasting.

Blood glucose was evaluated at the end of each consultation by an enzymatic semiquantitative method (Ames stix). The other blood specimens were brought daily to a laboratory in Gaborone for analysis.

QUESTIONNAIRE

The medical questionnaire contained questions regarding family and civil status, self assessed general health, health problems experienced during the previous month and additional questions focusing on smoking, taking snuff and alcohol consumption.

CLASSIFICATION OF HEALTH PROBLEMS

International Classification of Primary Care (ICPC) was used to classify both the elderly person's health problems and the diagnosis made by the doctor. ${ }^{7}$ The same doctor made all the final diagnosis, ensuring a consistent diagnosis setting. $5 .^{8}$

The data analysis was done using EPI-Info

\section{Results}

After an extensive search, we registered a total of 419 people assumed to be 60 years of age or above in the village. The number is higher than the 307 found in the national census that took place the same year. ${ }^{4}$ The difference may be a matter of delimiting the geographical area of inclusion, as well as fluctuations because of seasonal migration. The offer of a comprehensive medical examination could also have attracted people from areas outside the village to participate, inflating our figure somewhat.

Of the 419 elderly people registered, 337 $(83 \%)$ persons were included in the study, of which $228(68 \%)$ were women and $109(32 \%)$ men. The age was not recorded accurately in four patients, making the sample size of age distribution 333 persons. The oldest registered person was 100 years, and 14 were more than 90 years of age.

The civil status showed significant differences between the genders. The majority of the men were still married ( $87 \%$ ) while the majority of the women were widowed $(71 \%)$. There were few divorcees or single people among the elderly.

The findings from the household study have been published elsewhere and is briefly summarised here. ${ }^{23}$ The extended family living together was the most common form of cohabitation. Forty one per cent of the households consisted of 3-4 generations but with one of the middle generation missing. This supports the impression that village households have an overrepresentation of dependant members (old people, children, disabled people) and a tendency for the young people to seek employment in the urban areas. Close to half of the elderly (163) had six or more children alive. Still it was found that as much as $41 \%$ of the households with elderly members claimed to receive none or very irregular support from their children.

HEALTH PROBLEMS

The evaluation of the health related problems among the elderly people grouped into 15 major categories according to ICPC, is given in table 1 . This evaluation is made on basis of the medical examination, information from the questionnaire and test results. In all 1768 medical problems were identified, with an average of 5.2 problems per person. This is more than the number of self reported health problems, which was 1106 . The reasons for this

Table 1 Doctors evaluation of health related problems among the 337 elderly of Mmankgodi village grouped into 15 categories according to the ICPC classification system

\begin{tabular}{ll}
\hline Description & Total number (\%) \\
\hline General signs and symptoms & $85(5)$ \\
Blood & $4(0)$ \\
Digestive & $147(8)$ \\
Eye & $232(13)$ \\
Ear & $37(2)$ \\
Circulatory & $189(11)$ \\
Musculoskeletal & $446(25)$ \\
Neurology & $205(12)$ \\
Mental illnesses & $109(6)$ \\
Respiratory & $103(6)$ \\
Skin & $37(2)$ \\
Endocrine, metabolic and nutrition & $45(3)$ \\
Urinary & $91(5)$ \\
Female genital & $22(1)$ \\
Male genital & $16(1)$ \\
& $1768(100)$ \\
\hline
\end{tabular}




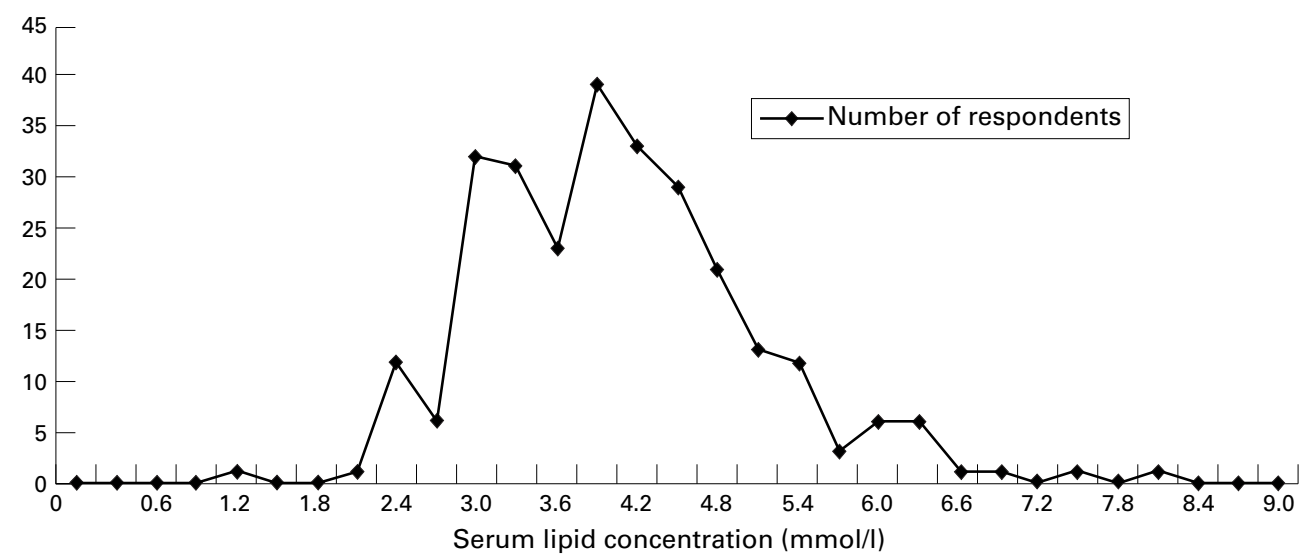

Figure 1 Serum lipids of elderly people of Mmankgodi village: 272 cholesterol samples.

discrepancy may be that many of the medical problems like minor cataract, heart rhythm irregularities, hypertension, glaucoma, etc, are asymptomatic.

The most prominent health problems were related to the musculoskeletal system, comprising 446 (25\%, CI 23 to 27$)$ of the problems. The two most frequently diagnosed musculoskeletal problems were lumbar pain, and neck/ shoulder pain.

Eye diseases were diagnosed 232 times (13\%, CI 12 to 15$)$ of all health problems, with cataract seen in $115(34 \%$, CI 29 to 40$)$ of the elderly. Thirty six $(11 \%$, CI 8 to 15$)$ were registered as blind. Glaucoma was registered among $30(9 \%$, CI 6 to 13$)$ of the elderly. 25 (7\%, CI 5 to 11 ) had increased pressure on one eye, while five had increased pressure on both eyes.

Neurological problems were the third most frequently seen category. The most common single diagnosis was headache, seen in 43 $(13 \%)$ of the elderly.

Circulatory problems comprised the fourth largest group with 189 entries. Sixty three persons (19\%, CI 15 to 23 ) had a previous undiagnosed pathological increased blood pressure. Additionally 37 persons had a known hypertension.

Mental problems were registered 109 times ( $6 \%$, CI 5 to 7$)$. There was no depression score system used, but depression was clinically diagnosed by the doctor in 32 cases (9\%, CI 7 to 13). This is based upon the answers from the questionnaire: (a) "Do you feel life is worthless?", (b) "Do you feel life is hopeless?" and (c) "Have you been thinking of taking your own life?" Eleven answered "yes" to (a), 13 answered "yes" to (b) and 10 answered "yes" to (c). There were 28 persons that answered "yes" to one or more of the above questions. The doctor added on clinical grounds another four persons to the list.

Nutritional status measured by BMI showed that $238(71 \%$, CI 65 to 75$)$ were registered with a normal BMI between 18.5 and 29.9, while 22 respondents (7\%) were registered with a BMI less than 16 , indicating severe malnutrition. An additional 47 (14\%, CI 11 to 18$)$ were registered as moderate malnourished with BMI between 16 and 18.5. Twenty five of the elderly $(7 \%$, CI 5 to 11$)$ were obese with a BMI of 30 or more, out of which 21 were women.

One person was registered as deaf, but 85 indicated they had some difficulties in hearing: 69 women (30\%, CI 24 to 37) and 16 men (15\%, CI 9 to 23$)$.

\section{LABORATORY RESULTS}

The mean haemoglobin value of the 220 women tested was $13.9 \mathrm{~g} \%$ (CI 13.7 to 14.1 , range $10.1-24.9 \mathrm{~g} \%$ ) and among the 99 men $14.6 \mathrm{~g} \%$ (CI 14.3 to 14.9 , range $10.5-19.9$ $\mathrm{g} \%$ ). Mean serum cholesterol was $4.19 \mathrm{mmol} / 1$ (CI 4.07 to 4.31 ) and mean serum triglycerides was $1.58 \mathrm{mmol} / 1$ (CI 1.50 to 1.66) (figs 1 and 2). Thirteen persons had a non-fasting blood

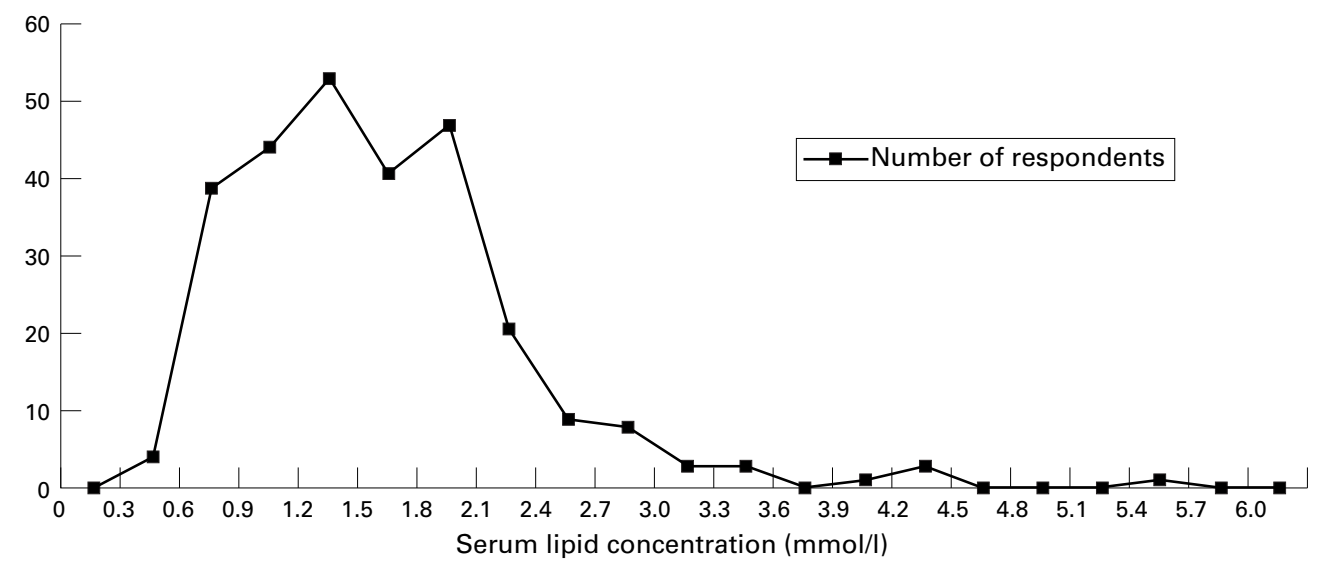

Figure 2 Serum lipids of elderly people of Mmankgodi village: 276 triglyceride samples. 
Table 2 Self evaluated health status and own health status compared with age mates among the elderly of Mmankgodi village

\begin{tabular}{|c|c|c|c|c|c|c|}
\hline & \multicolumn{2}{|c|}{ Women } & \multicolumn{2}{|c|}{ Men } & \multicolumn{2}{|c|}{ Total } \\
\hline & $n$ & $\%(95 \% C I)$ & $n$ & $\%(95 \% C I)$ & $n$ & $\%(95 \% C I)$ \\
\hline \multicolumn{7}{|l|}{ Health status } \\
\hline Good health & 40 & 18 (13 to 23$)$ & 40 & 37 (28 to 47$)$ & 80 & $24(19$ to 29$)$ \\
\hline Reduced health & 123 & $54(47$ to 61$)$ & 48 & $44(35$ to 54$)$ & 171 & $51(45$ to 56$)$ \\
\hline Poor health & 65 & $29(23$ to 35$)$ & 21 & $19(13$ to 28$)$ & 86 & $26(21$ to 31$)$ \\
\hline \multicolumn{7}{|c|}{ Compared with age mates } \\
\hline Better & 74 & $32(27$ to 39$)$ & 47 & 43 (34 to 53$)$ & 121 & $36(31$ to 41$)$ \\
\hline Same & 90 & 39 (33 to 46$)$ & 31 & $28(20$ to 38$)$ & 121 & $36(31$ to 41$)$ \\
\hline Worse & 59 & $26(20$ to 32$)$ & 30 & $28(20$ to 37$)$ & 89 & $26(22$ to 32$)$ \\
\hline \multirow[t]{2}{*}{ No answer } & 5 & $2(1$ to 5$)$ & 1 & $1(0$ to 6$)$ & 6 & $2(1$ to 4$)$ \\
\hline & 228 & 100 & 109 & 100 & 337 & 100 \\
\hline
\end{tabular}

glucose of $10 \mathrm{mmol} / \mathrm{l}$ or more, while $39 \mathrm{had}$ values between $7-10 \mathrm{mmol} / \mathrm{l}$. All the elderly tested HIV-antibody negative.

QUESTIONNAIRE

Two questions pertained to the elderly people's perception of their own health: one about how they rated their own general health on a three point scale, the other related to how they perceived their own health status as compared with age mates (table 2). Twenty four per cent stated to be in good health, men more so than women ( $37 \%$, CI 29 to 47 versus $18 \%$, CI 13 to 24). Compared with age mates, as many as 242 (72\%, CI 67 to 76$)$ considered their health to be the same or better.

Table 3 gives the self reported health problems. In total 1106 health problems were reported, with an average of 3.3 problems per person in the study population (3.6 per female and 2.6 per male). Nineteen persons ( $6 \%$ ) did not report any health problem, and five indicated they had a health problem without specifying it further.

The most frequently mentioned problems were related to the musculoskeletal system, regardless of gender. Alcohol related problems were not reported by any of the elderly.

A total of 210 persons (62\%, CI 57 to 67) reported being worried: 157 women $(69 \%$, CI 62 to 75 ) and 53 men ( $49 \%$, CI 39 to 58$)$. The three major reasons given for their worries were lack of care, lack of food, and health problems. One or several of these reasons were mentioned by a total of 162 ( $48 \%$, CI 43 to 54$)$ of the elderly.

Memory loss of various degrees were reported, as $36,(11 \%$, CI 8 to 15$)$ of the elderly

Table 3 Self reported health problems among 337 elderly of Mmankgodi village grouped according to the ICPC classification system

\begin{tabular}{llll}
\hline & Women n (\%) & Men n (\%) & Total n (\%) \\
\hline General signs and symptoms & $61(7)$ & $13(5)$ & $74(7)$ \\
Blood & $1(0)$ & & $1(0)$ \\
Digestive & $64(8)$ & $25(9)$ & $89(8)$ \\
Eye & $61(7)$ & $28(10)$ & $89(8)$ \\
Ear & $21(3)$ & $8(3)$ & $29(3)$ \\
Circulatory & $49(6)$ & $11(4)$ & $60(5)$ \\
Musculoskeletal & $349(42)$ & $104(37)$ & $453(41)$ \\
Neurology & $88(11)$ & $22(8)$ & $110(10)$ \\
Mental & $13(2)$ & $13(5)$ & $26(2)$ \\
Respiratory & $67(8)$ & $29(10)$ & $96(9)$ \\
Skin & $24(3)$ & $7(3)$ & $31(3)$ \\
Endocrine, metabolic and nutrition & $1(0)$ & & $1(0)$ \\
Urinary & $12(1)$ & $18(6)$ & $30(3)$ \\
Female genital & $16(2)$ & & $16(1)$ \\
Male genital & $827(100)$ & $279(100)$ & $1106(100)$ \\
& & & \\
\hline
\end{tabular}

KEY POINTS

- Elderly people in developing contries are rarely targeted for studies on morbidity and health care utilisation.

- The most frequently found health problems were related to the musculoskeletal system.

- Worries are similar (more so among women than men) and their complaints focus on lack of care and food in addition to health problems.

- There is a need to develop health care programmes especially directed to the elderly population.

answered that the memory was somewhat reduced and four said that it was much reduced. The memory was also tested by asking the participants to remember and repeat three words five minutes after they were spoken. One hundred and sixty two $(48 \%$, CI 43 to 54 ) were able to repeat all three words, 126 (38\%, CI 32 to 43) remembered two, 38 $(11 \%$, CI 8 to 15$)$ remembered one, while 10 ( $3 \%$, CI 2 to 6$)$ could not remember any of the three words.

Thirty seven ( $11 \%$, CI 8 to 15$)$ of the respondents smoked daily. Twenty six $(70 \%$, CI 53 to 84 ) of the daily smokers consumed more than 15 cigarettes per day. Almost all of the daily smokers were men, only one was female. Taking snuff was a common habit among the elderly, as 115 (50\%, CI 44 to 57$)$ of the women and 36 (33\%, CI 25 to 43$)$ of the men took snuff more than twice daily.

Alcohol was regularly consumed by 188 ( $56 \%$, CI 50 to 61 ) of the elderly, more often so by men than women, $87(80 \%$, CI 71 to 87$)$ versus $101(44 \%$, CI 38 to 51$)$. The home made beer called "bojalwa" is the most popular drink. Bojalwa was consumed daily or almost daily by 74 (22\%, CI 18 to 27$)$ persons, 28 women (12\%, CI 8 to 17$)$ and 46 men ( $42 \%$, CI 33 to 52). Bojalwa is made of sorghum, has a high energy content (equivalent to milk) and is rich in vitamin Bs and iron. The second most popular beer-type is industrialised bojalwa produced and sold commercially. ${ }^{9}$ Among men aged 80 or older, 18 of 20 confirmed they were drinking bojalwa daily or almost daily.

UTILISATION OF HEALTH CARE

The respondents were asked about their utilisation of health care needs during the past month. The most common place to seek treatment for their health problems was the nearest clinic visited by 75 (22\%, CI 18 to 27$)$ of the respondents. Another 65 persons had one or several times visited other medical facilities in the region, bringing the figure to a total of 140 persons ( $42 \%$, CI 36 to 47 ).

Thirty five of the elderly $(10 \%$, CI 7 to 14$)$ had sought help from a traditional healer during the past month.

A majority of 238 persons $(71 \%$, CI 65 to 75) did not seek assistance from anybody for their worries. Of the $99(29 \%$, CI 25 to 35$)$ that did seek help, 74 were women and 25 men. For 
these problems, "modern" medicine was not the preferred venue. The relatives were the most common place to seek help, chosen by $69 \%$ of the help seekers. Nine went to the local chief and 16 visited the local clinic.

\section{Discussion}

The results of the study have given insight into the health and the living conditions of the elderly people of Mmankgodi village in Botswana. Although Mmankgodi is not obviously different from other villages in the country, the results should not be generalised or used as national data. To obtain such information, it will be necessary to conduct a larger study with a stratified sample.

There is a majority of women in the sample. The gender difference increases with increasing age. In the age group of 85 years and older, the women outnumber men more than 3 to 1 . The major reason for the gender differences is that the life expectancy at birth is more favourable for women than for men: 65.9 years as compared with $59.4 .^{10}$

Little is known about the elderly and nutrition in Botswana. Among our group of elderly, $69(21 \%)$ were classified as moderate or severely malnourished. This indicates that malnutrition is a significant health problem among the elderly in this region. It should be an area for further investigations, particularly when it comes to major causes and prevention of malnutrition.

Musculoskeletal problems are frequent, close to half of the self reported problems relate to this. The same tendency is seen in studies from other African countries, indicating it to be a common problem among elderly people of this continent. ${ }^{11} 12$

Increased blood pressure was registered in $19 \%$ of the participants, the same level as that found in a Nigerian study of elderly. ${ }^{11}$ Only two persons with a physical disability related to stroke were observed, which is less than could be expected in this age group. One explanation could be that risk factors of cardiovascular diseases like high level of serum lipids and daily cigarette smoking were relatively rare in our study. The same favourable results concerning serum lipids are found in a study from Southern Africa. ${ }^{13}$ The few sequels of stroke seen among the elderly, could also be attributable to a high mortality from this disease in younger age groups.

Blindness was the single most frequently found physical disability, affecting $10 \%$ of the study population. The majority suffered from cataract, a condition that can be surgically treated. The procedure for operation is relatively simple, and is carried out at three hospitals in Botswana.

Taking snuff was frequently enjoyed by the elderly of both sexes. Complications and risk factors related directly to taking snuff are not well known. In a recent review article it was concluded that the long term effects of taking snuff seem to be below the health risks of smoking tobacco. ${ }^{14}$

Alcoholic beverages are frequently consumed by the elderly, and more often by men than women. Home made beer was the most popular drink. The health hazards related to drinking of home made beer are probably less compared with that of other alcoholic beverages, like industrial spirits and beers, as these have higher alcoholic content and are less nutritious. It is however known that high consumption of alcohol is connected to many different problems such as physical fights, family violence and poverty in the household. This study did not explore the quantities or qualities of problems attributable to alcohol consumption. The high level of daily or almost daily alcohol consumption among the elderly should however be an area of future research.

A substantial number of participants experienced worries, more often so women than men. This despite the fact that the majority of the elderly do have many children, whom traditionally have taken responsibility to assist their elderly family members. If, as it seems from this study and the household study, the traditional support system is no longer functioning as it used to, it will have considerable consequences for the future planning of a health care system for the elderly in this part of Africa. Although no depression score system was used, many of the elderly expressed that life was worthless, hopeless, and some (10 persons) had been thinking of taking their own lives. This supports the finding that life is experienced difficult for some of the elderly.

The elderly people are using the healthcare system in different ways depending on the nature of the problem. When experiencing somatic health problems, more than $90 \%$ consult the local clinic. Another pattern emerges when dealing with worries, most of the elderly carry their worries on their own, but when seeking advice, the relatives were preferred.

It was somewhat surprising to find that traditional doctors were not used more often by the elderly people. It seems that the traditional doctors are consulted for more specific familiar or interpersonal problems related to tradition and beliefs rather than for typical health problems. ${ }^{15}$

The HIV epidemic had not yet reached the elderly people in Mmankgodi when the survey was carried out (1991). This despite its proximity to Gaborone, where the prevalence has been steadily increasing over the past years. According to Botswana tradition, elderly men may have sexual relations with young girls as a way of retaining youth and virility. The risk of being infected by HIV of the elderly generation is hence likely in the future, and even the elderly should be included in the preventive measures to be taken against the epidemic.

There has never been any specific health programme in Botswana aiming at the elderly as a group. Health programmes targeting the elderly could relatively easily identify those with severe depression, malnutrition and disabilities such as blindness. Most persons with hazardous alcohol drinking pattern can also be identified. Programmes aimed at the elderly should be integrated in the present primary health care system, in line with programmes for women and children. 
The Botswana Government recently introduced a pension for the elderly above 65 years of age of 100 Pula (25 \$US) per month, indicating that they officially have recognised the elderly as an important population group in need of assistance.

The study was planned and implemented by Dr Edwin Sandberg, who was responsible for $94 \%$ of the fieldwork. He also did the data entering. He later became seriously ill, and died in the autumn of 1993.

Funding: the project has been made possible through grants rom the Norwegian Research Council for Science and Humanities, Royal Norwegian Ministry of Foreign Affairs, Helpage International, Anders Jahre's Medical Fund, and Thordis and Johannes Gahr's Fund for the Benefit of Geropsychiatric Research

Conflicts of interest: none.

1 Kalache A. Ageing in developing countries. In: Pathy MSJ, ed. Principles and practice of geriatric medicine. 2 nd ed. London: John Wiley, 1991:22-32.

2 Ingstad B, Brunborg $\mathrm{H}$, Bruun F. Elderly people at village level in Botswana. Yearbook of population research 1996:24361.

3 Ingstad B, Bruun F, Sandberg E, et al. Care for the elderlycare by the elderly-the role of elderly women in changing Tswana society. fournal of Cross-cultural Gerontology 1996; 7:379-98.
4 Central Statistics Office. 1991 Population and housing census. Gaborone: The Government Printer, 1994.

5 WHO/ISF Fifth Mild Hypertension Conference. Guidelines for the management of mild hypertension. F Hypertens 1989;7:689-93.

6 James WPT. Definition of chronic energy deficiency in adults. Report of a Working Party of the International
Dietary Energy Consultative Group. Eur f Clin Nutr 1988; 42:968-81.

7 WONCA. International classification of primary care. Oxford: Oxford Medical Publications, 1987.

8 Dean AG, Dean JA, Burton AH, et al. EPI Info Version 5: a word processing, database, and statistics program for epidemiolgy on microcomputers. Stone Mountain: USD, 1990.

9 Helle-Valle J, Holmboe-Ottesen G, McNeill D. Modernisation and beer consumption in Botswana. Oslo: Centre for Development and the Environment (SUM) University of Oslo, 1994.

10 The Government of Botswana. The situation analysis of children and women in Botswana. Gaborone: Maendeleo, 1993.

11 Bella AF, Baiyewu O, Bamigboye A, et al. The pattern of medical illness in a community of elderly Nigerians. Cent Afr f Med 1992;39:112-16.

12 Wilson AO, Adamchak DJ, Nyanguru AC, et al. A study of well being of elderly people in three communities in Zimbabwe. Age Ageing 1991;4:275-9.

13 Watermeyer GS, Mann JI, Truswell AS. Serum lipids in Ovambos. S Afr Med f 1972;46:1390-3.

14 Steen T. Health hazards of oral moist snuff (in Norwegian). Tidsskr Nor Legeforen 1996;116:625-7.

15 Tlou SD, Sandberg E. The elderly and their use of the health care system. In: Bruun FJ, Mugabe M, Coombes Y, eds. The situation of the elderly in Botswana. Oslo: Lobo Grafisk, 1994: 93-9. 